\title{
Barium stable isotopes in the Ganga (Hooghly) River estuary, India
}

\author{
TARUN K. DALAI ${ }^{1}$, TRISTAN J. HORNER ${ }^{2}$
}

${ }^{1}$ Department of Earth Sciences, IISER Kolkata, India

(dalai@iiserkol.ac.in)

${ }^{2}$ Woods Hole Oceanographic Institution, USA

(tristan.horner@whoi.edu)

Barium (Ba) mass balance of rivers and estuaries is strongly influenced by solute-particle interactions [1]. These interactions, principally estuarine desorption of $\mathrm{Ba}$ from suspended particulate matter (SPM), can enhance Ba fluxes to coastal seawater by orders of magnitude. However, these processes have hitherto escaped Ba-isotopic characterization, rendering mass balances incomplete. Here, we constrain this important term by investigating the Ba-isotopic systematics of the Ganga (Hooghly) River estuary. The Ganga constitutes the largest river system in India and is characterized by a high SPM load. Previous studies showed solute-particle interactions in this estuary can increase riverine Ba fluxes by $>300 \%$ [2]. Barium-isotopic data were obtained for both dissolved and SPM phases (bulk and exchangeable) across periods of contrasting water discharge. We find that dissolved $\delta^{138 / 134} \mathrm{Ba}$ varies between $\sim+0.1$ to $+0.2 \%$ (relative to NIST SRM 3104a), and, outside of the lowermost estuary, is broadly negatively correlated with salinity. Dissolved $\delta^{138} \mathrm{Ba}$ values are consistently lower-than-expected from conservative mixing of sea- and river water. Bulk SPM exhibits a narrow Ba-isotopic range centred on $\sim 0 \%$, with no salinity dependence. In contrast, exchangeable SPM exhibits a decrease in $\delta^{138} \mathrm{Ba}$ with salinity, which correlates with the fraction of $\mathrm{Ba}$ lost via desorption. Together, these observations indicate that desorbed $\mathrm{Ba}$ is isotopically heavier than either bulk particulate or exchangeable $\mathrm{Ba}$ in freshwater, but is lighter than riverine $\mathrm{Ba}$. An increase in dissolved $\delta^{138} \mathrm{Ba}$ in the lowermost estuary is presumed to reflect removal of light $\mathrm{Ba}$, which could occur through either (re)adsorption or barite precipitation. Overall, this study indicates that the solute-particle interactions that increase $\mathrm{Ba}$ fluxes from estuaries also work to lower $\delta^{138} \mathrm{Ba}$ toward more crustal compositions (i.e., $\sim 0 \%$ [3]). If true elsewhere, the net $\mathrm{Ba}$ flux from land to coastal seawater is likely isotopically lighter than river water. The isotopic make-up of continental Ba flux thus critically depends on the amount of riverine SPM and the loci of interaction with saltwater, both of which will reflect the prevailing tectonics and climate.

[1] Stecher \& Kogut (1999) Geochim. Cosmochim. Acta 63, 10031012. [2] Samanta \& Dalai (2016) Geochim. Cosmochim. Acta 195, 1-28. [3] Nan et al. (2018), Geochim. Cosmochim. Acta 233, 33-49. 